\title{
CONCENTRAÇÃO DE ÁCIDO TARTÁRICO DOS VINHOS DA SERRA GAÚCHA
}

\author{
TARTARIC ACID CONTENT IN WINES FROM THE SERRA GAÚCHA REGION
}

\author{
Luiz Antenor Rizzon ${ }^{1}$ Alberto Miele ${ }^{2}$
}

Tendo em vista a importância do ácido tartárico na composição química e na qualidade do vinho, realizou-se o presente trabalho com o objetivo de determinar o seu teor nos vinhos da Serra Gaúcha. Analisaram-se 288 amostras de vinhos tintos Isabel, Cabernet Sauvignon, Cabernet Franc e Merlot e de vinhos brancos Chardonnay, Riesling Itálico e Moscato. As análises foram feitas através da cromatografia líquida de alta eficiência (CLAE). Os resultados evidenciaram que o teor médio do ácido tartárico do vinho Isabel $\left(5,0 \mathrm{~g} \mathrm{~L}^{-1}\right)$ foi significativamente maior que o teor dos demais vinhos. Numa classificação inferior ao vinho Isabel, ficou o vinho Riesling Itálico $\left(3,1 \mathrm{~g} \mathrm{~L}^{-1}\right)$ que foi similar à do Chardonnay $\left(2,6 \mathrm{~g} \mathrm{~L}^{-1}\right)$, mas significativamente maior que as concentrações dos vinhos Cabernet Sauvignon $\left(2,2 \mathrm{~g} \mathrm{~L}^{-1}\right)$, Cabernet Franc $\left(2,3 g L^{-1}\right)$, Merlot $\left(2,4 g L^{-1}\right)$ e Moscato $\left(2,2 g L^{-1}\right)$.

Palavras-chave: vinho, composição química, ácido tartárico.

\section{SUMMARY}

Due to the importance of tartaric acid in the composition and quality of wines, this work aimed to determine its concentration in wines from the highlands in Rio Grande do Sul, Brazil. A total of 288 samples of the red wines Isabella, Cabernet Sauvignon, Cabernet Franc, and Merlot and of the white wines Chardonnay, Italic Riesling and White Muscat were analysed by HPLC. Results showed that the average concentration of tartaric acid in Isabella $\left(5.0 \mathrm{~g} \mathrm{~L}^{-1}\right)$ was significantly higher than in other wines; the concentration of the tartaric acid in Italic Riesling (3.1 $\left.\mathrm{g} \mathrm{L}^{-1}\right)$ wine was similar to the Chardonnay $\left(2.6 \mathrm{~g} \mathrm{~L}^{-1}\right)$ but significantly higher than the concentrations found in the wines of Cabernet Sauvignon (2.2g L $\left.L^{-1}\right)$, Cabernet Franc $\left(2.3 g L^{-1}\right)$, Merlot $\left(2.4 \mathrm{~g} \mathrm{~L}^{-1}\right)$ and White Muscat $\left(2.2 \mathrm{~g} \mathrm{~L}^{-1}\right)$.
Key words: wine, chemical composition, tartaric acid.

Entre os ácidos orgânicos da uva, o tartárico é o mais importante. É um ácido específico da uva e a videira é uma das raras plantas que o sintetiza em quantidade elevada, possibilitando sua extração comercial (RUFFNER, 1982; CHAMPAGNOL, 1984; FLANZY, 1998; HUGLIN \& SCHNEIDER, 1998). Na fase de formação da uva, o teor de ácido tartárico do mosto é de aproximadamente $15,0 \mathrm{~g} \mathrm{~L}^{-1}$, diminuindo para $6,0 \mathrm{~g} \mathrm{~L}^{-1}$ a $7,0 \mathrm{~g} \mathrm{~L}^{-1}$ no período de maturação da uva, devido principalmente à sua dissolução no mosto em função do aumento do tamanho da baga. Na fermentação alcoólica, o teor de ácido tartárico diminui ainda mais, em conseqüência da insolubilização e precipitação do tartarato ácido de potássio (cremor de tártaro) (RIBÉREAUGAYON et al., 1976). A literatura cita que o teor de ácido tartárico normalmente encontrado no vinho estabilizado é de $1,5 \mathrm{~g} \mathrm{~L}^{-1}$ a $3,0 \mathrm{~g} \mathrm{~L}^{-1}$ e depende do tipo de vinho (NAVARRE, 1991; USSEGLIOTOMASSET, 1995).

Sob o ponto de vista químico, o ácido tartárico é um biácido, cujo peso molecular é de 150,09, encontrado no vinho na forma $\mathrm{L}(+)$ (RIBÉREAU-GAYON et al. 1976; USSEGLIOTOMASSET, 1995). É entre os ácidos orgânicos do

\footnotetext{
${ }^{1}$ Engenheiro Agrônomo, Doutor, Embrapa Uva e Vinho, CP 130, 95700-000, Bento Gonçalves, RS. E-mail: rizzon@cnpuv.embrapa.br. Autor para correspondência.

${ }^{2}$ Engenheiro Agrônomo, Doutor, Embrapa Uva e Vinho. E-mail: miele@cnpuv.embrapa.br. Bolsista do CNPq. 
vinho o mais forte, por isso influi de modo determinante no $\mathrm{pH}$ e nas características sensoriais dos vinhos. Quando presente em grande quantidade, confere aspereza e mesmo certa adstringência ao vinho; mas, em concentrações adequadas é responsável pela fineza ácida dos bons produtos. Encontrase na forma livre e salificada, nesse caso, especialmente com o potássio.

$\mathrm{Na}$ Serra Gaúcha do Rio Grande do Sul (RS), pouco se conhece sobre o teor de ácido tartárico dos diferentes tipos de vinhos. RIZZON \& MIELE (1997) determinaram a concentração de ácido tartárico do vinho Cabernet Sauvignon produzido e comercializado no Brasil. Os valores detectados variaram entre $1,8 \mathrm{~g} \mathrm{~L}^{-1}$ e $2,1 \mathrm{~g} \mathrm{~L}^{-1}$. RIZZON $\boldsymbol{e t}$ al. (1998) verificaram que ocorreu redução do teor de ácido tartárico na vinificação em tinto das uvas Merlot, Cabernet Franc e Cabernet Sauvignon de Bento Gonçalves, Santana do Livramento e Pinheiro Machado, no Rio Grande do Sul.

No mosto, DAUDT et al. (1991) e GUERRA et al. (1992) acompanharam a evolução do ácido tartárico na maturação das principais uvas utilizadas para elaboração de vinho fino na Serra Gaúcha e constataram redução importante no período de maturação.

Tendo em vista a importância do ácido tartárico na composição química do vinho e a pouca disponibilidade de informações, realizou-se o presente trabalho com o objetivo de determinar o teor de ácido tartárico nos vinhos da Serra Gaúcha.

Foi determinado o teor de ácido tartárico em 233 vinhos tintos - Isabel (33), Cabernet Sauvignon (62), Cabernet Franc (80) e Merlot (58) -. Analisaram-se, ainda, 55 vinhos brancos - Chardonnay (20), Riesling Itálico (26) e Moscato (9). A amostragem foi realizada de 1995 a 1999, representada por vinhos comerciais e provenientes das edições da Avaliação Nacional de Vinhos.

O ácido tartárico foi analisado através da cromatografia líquida de alta eficiência (CLAE), em um aparelho Perkin Elmer, que funcionou em condição isocrática, equipado com um injetor Rheodyne de $20 \mu \mathrm{L}$ de volume e um detector Diodo Aray 235C. A separação do ácido tartárico foi realizada em fase reversa, com uma coluna Varian MCH-NCAP-5 de $15 \mathrm{~cm}$ de comprimento por 4,6mm de diâmetro interno (AUGUSTE, 1979). A leitura foi feita a $212 \mathrm{~nm}$. Para a eluição, utilizou-se um solvente constituído de água ultrapura, acidificada com ácido fosfórico a pH 2,5. Para o cálculo da concentração, utilizou-se o método de padronização externo.

Utilizou-se delineamento inteiramente casualizado com número diferente de repetições. Os resultados obtidos foram submetidos à análise de variância e ao teste de Tukey, para comparação das médias do ácido tartárico de cada tipo de vinho e, também, ao cálculo do intervalo de confiança.

O teor de ácido tartárico dos vinhos da Serra Gaúcha está indicado na tabela 1. Constatou-se teor médio mais elevado de ácido tartárico no vinho Isabel, duas vezes maior em relação aos demais vinhos varietais tintos estudados. Isso ocorreu devido à composição da uva, especialmente da película, pois há uma maior concentração de ácido tartárico na película da uva Isabel em relação às uvas tintas de Vitis vinifera. Outro aspecto que pode ter contribuído para o teor mais elevado de ácido tartárico no vinho Isabel foi o tamanho da baga. A uva Isabel apresenta baga maior, logo uma proporção película/polpa diferente em relação às outras uvas tintas. Esse fato determina menor concentração de potássio no mosto, visto que os elementos minerais estão mais concentrados na parte sólida da uva (RIBÉREAU-GAYON et $\boldsymbol{a l}$., 1976; USSEGLIOTOMASSET, 1995). Conseqüentemente, a salificação e a precipitação do ácido tartárico é menor.

Os demais vinhos varietais tintos não apresentaram diferenças significativas em relação ao teor de ácido tartárico. A concentração desse ácido no vinho Cabernet Sauvignon correspondeu ao encontrado nos vinhos comerciais dessa cultivar (RIZZON \& MIELE, 1997). Em relação ao coeficiente de variação, observaram-se valores mais elevados para os varietais brancos estudados, devido à maior variabilidade do teor de ácido tartárico do mosto e ao sistema de vinificação utilizado.

Tabela 1 - Teor de ácido tartárico em g $\mathrm{L}^{-1}$ de vinhos da Serra Gaúcha.

\begin{tabular}{|c|c|c|c|c|c|}
\hline Tipo de vinho & $\begin{array}{c}\text { Amostra } \\
\left(n^{\circ}\right)\end{array}$ & $\begin{array}{l}\text { Intervalo de } \\
\text { confiança }^{1}\end{array}$ & \multicolumn{2}{|c|}{ Média $^{2}$} & $\begin{array}{l}\mathrm{CV} \\
(\%)\end{array}$ \\
\hline \multicolumn{6}{|l|}{ Vinho tinto } \\
\hline Isabel & 33 & $4,6-5,3$ & $5,0 \mathrm{a}$ & & 13,9 \\
\hline Cabernet Sauvignon & 62 & $2,1-2,3$ & 2,2 & $\mathrm{c}$ & 15,4 \\
\hline Cabernet Franc & 80 & $2,2-2,5$ & 2,3 & $\mathrm{c}$ & 17,4 \\
\hline Merlot & 58 & $2,3-2,6$ & 2,4 & $\mathrm{c}$ & 13,2 \\
\hline \multicolumn{6}{|l|}{ Vinho branco } \\
\hline Chardonnay & 20 & $2,2-3,1$ & $2,6 \mathrm{~b}$ & bc & 27,0 \\
\hline Riesling Itálico & 26 & $2,5-3,7$ & $3,1 \quad b$ & b & 33,8 \\
\hline Moscato & 9 & $1,5-2,9$ & 2,2 & $\mathrm{c}$ & 28,3 \\
\hline
\end{tabular}

${ }^{1}$ Nível de probabilidade do intervalo de confiança $=99 \%$.

${ }^{2}$ Médias seguidas por letras distintas na coluna diferem entre si, pelo teste de Tukey a $1 \%$ de probabilidade. Prob. $>\mathrm{F}=0,00001$; $\mathrm{CV}=19,8 \%$. 
Quanto aos vinhos brancos, o varietal Riesling Itálico apresentou um teor de ácido tartárico mais elevado que o vinho Moscato, mas não diferiu significativamente do Chardonnay. O teor mais baixo de ácido tartárico do vinho Moscato foi, provavelmente, devido à correção da acidez, visto que essa cultivar se caracteriza por apresentar mosto com acidez elevada. Correção excessiva do teor de ácido tartárico reduz o frescor, característica de qualidade para o vinho branco.

\section{REFERÊNCIAS BIBLIOGRÁFICAS}

AUGUSTE, M.H. Application de la chromatographie en phase liquide à haute pression à l'analyse des moûts et des vins. Talence, France, 1979. 135p. Tese (Doutorado em Viticultura e Enologia) - Université de Bordeaux II, 1979.

CHAMPAGNOL, F. Élements de physiologie de la vigne et de viticulture générale. Montpellier: Déhan, 1984. 351p.

DAUDT, C.E., GUERRA, C.C., RIZZON, L.A. Evolução dos ácidos tartárico e málico em uvas cultivadas no Rio Grande do Sul (Brasil). I. Vitis vinifera Riesling Renano, Gewurztraminer e Verduzzo. Ciência e Tecnologia de Alimentos, Campinas, v.11, n.2, p.181-199, 1991.

FLANZY, C. Oenologie. Fondements scientifiques et technologiques. Paris : Lavoisier-Tec \& Doc, 1998. 1311p.
GUERRA, C.C., DAUDT, C.E., RIZZON, L.A. Evolução dos teores dos ácidos tartárico e málico durante a maturação de uvas tintas. Pesquisa Agropecuária Brasileira, Brasília, v.27, n.3, p.479-491, 1992.

HUGLIN, P.; SCHNEIDER, G. Biologie et écologie de la vigne. 2.ed. Paris : Lavoisier-Tec \& Doc, 1998. 370p.

NAVARRE, C. L'Oenologie. Paris : Lavoisier-Tec \& Doc, 1991. 322p.

RIBÉREAU-GAYON, J., PEYNAUD, E., RIBÉREAU-GAYON, P., et al. Sciences et techniques du vin. Paris : Dunod, 1976. V.1. 671p

RIZZON, L.A., MIELE, A. Caractéristiques analytiques des vins Cabernet Sauvignon produits et commercialisés au Brésil. In: IN VINO ANALYTICA SCIENTIA, 1, 1997, Bordeaux. Livre de résumés... Bordeaux : Fédération Européenne des Sociétés Chimiques/Société Française de Chimie/Office International de la Vigne et du Vin, 1997. p.478-481.

RIZZON, L.A., ZANUZ, M.C., MIELE, A. Evolução da acidez durante a vinificação de uvas tintas de três regiões vitícolas do Rio Grande do Sul. Ciência e Tecnologia de Alimentos, Campinas, v.18, n.2, p.179-183, 1998.

RUFFNER, H.P. Metabolism of tartaric and malic acids in Vitis: A review. Vitis, Siebeldingen, v.21, n.3, p.247-259, 1982.

USSEGLIO-TOMASSET, L. Chimica enologica. Brescia : AEB, 1995. 431p.

Ciência Rural, v. 31, n. 5, 2001. 